\title{
Decreased Pseudomonas aeruginosa biofilm formation on nanomodified endotracheal tubes: a dynamic lung model
}

This article was published in the following Dove Press journal:

International Journal of Nanomedicine

9 August 2016

Number of times this article has been viewed

\author{
Mary C Machado' \\ Thomas J Webster ${ }^{2}$ \\ 'Center for Biomedical Engineering, \\ Division of Engineering Brown \\ University, RI, USA; '2Department of \\ Orthopaedics, Division of Engineering \\ Brown University, RI, USA
}

\begin{abstract}
Ventilator-associated pneumonia (VAP) is a serious complication of mechanical ventilation that has been shown to be associated with increased mortality rates and medical costs in the pediatric intensive care unit. Currently, there is no cost-effective solution to the problems posed by VAP. Endotracheal tubes (ETTs) that are resistant to bacterial colonization and that inhibit biofilm formation could provide a novel solution to the problems posed by VAP. The objective of this in vitro study was to evaluate differences in the growth of Pseudomonas aeruginosa on unmodified polyvinyl chloride (PVC) ETTs and on ETTs etched with a fungal lipase, Rhizopus arrhizus, to create nanoscale surface features. These differences were evaluated using an in vitro model of the pediatric airway to simulate a ventilated patient in the pediatric intensive care unit. Each experiment was run for 24 hours and was supported by computational models of the ETT. Dynamic conditions within the ETT had an impact on the location of bacterial growth within the tube. These conditions also quantitatively affected bacterial growth especially within the areas of tube curvature. Most importantly, experiments in the in vitro model revealed a $2.7 \mathrm{log}$ reduction in the number (colony forming units $/ \mathrm{mL}$ ) of $P$. aeruginosa on the nanoroughened ETTs compared to the untreated PVC ETTs after 24 hours. This reduction in total colony forming units $/ \mathrm{mL}$ along the $x$-axis of the tube was similar to previous studies completed for Staphylococcus aureus. Thus, this dynamic study showed that lipase etching can create surface features of nanoscale roughness on PVC ETTs that decrease bacterial attachment of $P$. aeruginosa without the use of antibiotics and may provide clinicians with an effective and inexpensive tool to combat VAP.
\end{abstract}

Keywords: biofilm, laminar flow, ventilator-associated pneumonia, nanotechnology, endotracheal tubes, Pseudomonas aeruginosa

\section{Introduction}

A serious complication of mechanical ventilation, namely ventilator-associated pneumonia (VAP), is a hospital-acquired infection that targets a critically ill population in the pediatric intensive care unit (PICU). VAP is the second most common nosocomial infection in the PICU and affects 3\%-10\% of all children on mechanical ventilation. ${ }^{1,2}$ Infants and children from 2 months to 12 months of age have the highest age-specific rate of VAP. ${ }^{3}$ Infections such as VAP lead to increased mortality ${ }^{4}$ and morbidity. ${ }^{2,5,6}$ Additionally, VAP has been shown to increase the duration of mechanical ventilation by up to 11 days, ${ }^{2}$ increasing stays in the $\mathrm{PICU}^{6}$ and hospital costs by as much as $\$ 55,882 .^{7}$ Two of the pathogens most commonly associated with all VAP in the pediatric population are Staphylococcus aureus and Pseudomonas aeruginosa. ${ }^{3,8}$

VAP presents a difficult problem to the PICU, because it is often hard to distinguish pneumonia from tracheal colonization or other conditions common in mechanically
Correspondence: Thomas J Webster Department of Chemical Engineering, Northeastern University, 360 Huntington Avenue, Boston, MA 02115, USA $\mathrm{Tel}+\mathrm{I} 6173736585$ Email th.webster@neu.edu 
ventilated patients. ${ }^{3}$ Diagnosis of VAP is carried out using radiological, clinical, and microbiological criteria, but none of these measures has proven to be adequately sensitive and specific. ${ }^{9}$ To diagnose VAP effectively, bacterial colonization in the upper airway needs to be differentiated from lower airway infections. Misleading results can lead to inadequate, inappropriate, and delayed antimicrobial therapy, which has been shown to increase mortality, hospital stay, and cost from VAP. ${ }^{7,10}$ Therapy for VAP already accounts for $~ 50 \%$ of antibiotic use in PICUs. ${ }^{11}$ Prolonged antibiotic use can lead not only to the emergence of multidrug-resistant strains of bacteria in critically ill patients of the PICU but also to increased healthcare costs. ${ }^{12}$

Unlike many of the diseases that develop within the hospital environment, VAP is uniquely tied to the invasive devices used during ventilation, namely, the endotracheal tube (ETT). As with any other medical device implanted within the body, the ETT is exposed to numerous pathogens. Intubation with an ETT can compromise some of the body's natural defenses like coughing and mucociliary motion of the trachea, providing a direct route from the outside environment to the lungs. ${ }^{13}$

One of the key challenges toward inhibiting bacterial growth on ETTs occurs when bacteria exude an exopolysaccharide. Bacteria in this type of an extracellular matrix, or biofilm, result when they attach to an ETT surface, proliferate exponentially, and are especially tolerant to antibiotics administered to the patient. ${ }^{14}$ Biofilms on the inner lumen of the ETT are thought to be a significant source of bacterial colonization of the lungs. Ventilation through infected ETTs, or even condensation of humidified air, can break off portions of this biofilm, bringing bacteria deeper into the lungs and spurring growth on other areas of the tube. ${ }^{15}$

The unique properties of nanomodified surfaces (or surfaces with features $<100 \mathrm{~nm}$ in one direction) could provide a solution to the persistent problems of VAP. ${ }^{16}$ Nanomodified surfaces mimic the natural dimensions of the constituents of the human body and influence the activity of cells on these surfaces. In fact, cells and tissues within the human body are composed of micro and nanoscale building blocks. ${ }^{17}$ In addition, nanomaterials have unique surface energetics due to their significantly larger surface area than nanosmooth materials. Bacterial adhesion to these surfaces is undoubtedly influenced by these changes in surface energy. ${ }^{18}$ The large surface-to-volume ratio of nanomaterials has been shown to inhibit bacterial attachment and promote nonbacterial cell (such as osteoblasts, smooth muscle cells, endothelial cells, and chondrocytes) adhesion. ${ }^{19}$ The type, concentration, conformation, and bioactivity of proteins adsorbed onto a material depend on its surface chemistry, hydrophilicity, charge, topography, roughness, and energy, all of which can be influenced by nanotechnology. ${ }^{18}$ Bacterial adhesion can also be affected by properties such as roughness, stiffness, and topography. ${ }^{20,21}$ Reducing bacterial adhesion on the inner lumen of the ETT could reduce biofilm formation and perhaps prevent further colonization of the tube itself.

Moreover, in the past, studies on VAP have focused on modeling biofilm formation in straight adult ETTs under static conditions. However, fluid and air within curved tubes, like ETTs, display unique secondary flows. ${ }^{22}$ These vortical flows have been shown to affect the structure of a biofilm in hydrodynamic flow, causing streamer formation. It has become increasingly apparent that biofilms can alter their structural properties in response to fluid effects (such as shear stress), both resisting detachment and facilitating further colonization in the ETT. ${ }^{23-25}$

Nanomodified surfaces also influence biofilm structure. Biofilms growing on these surfaces have shown altered levels of extracellular polymeric substances as well as changes in colony shape and size. ${ }^{21}$ Therefore, dynamic tests of nanomodified surfaces are necessary to characterize the full antimicrobial potential of these novel materials, especially for ETT applications.

In view of the abovementioned factors, the objective of this in vitro study was to fabricate and test $P$. aeruginosa functions on nanomodified ETTs (without the use of antibacterials), under simulated dynamic lung conditions.

\section{Materials and methods Nanomodification of ETTs}

In this study, polyvinyl chloride (PVC; $13.5 \mathrm{~cm}$ ) ETTs $\left(\right.$ Sheridan $^{\circledR}$; Hudson RIC, Temecula, CA, USA) were modified to create nanoroughened surfaces. A fungal lipase was used to enzymatically degrade the polymer material and create nanofeatures on both the inner and outer surfaces of the tube. Briefly, PVC ETTs were exposed to a $0.1 \%$ mass solution of a Rhizopus arrhisus (Sigma-Aldrich Co., St Louis, MO, USA) lipase dissolved in a potassium phosphate buffer. $R$. arrhisus was chosen based on prior work, which demonstrated that this lipase degrades the polymer surface to create nanoscale features. ${ }^{16,26}$ This mixture was pipetted into the inner lumen of each tube until full, and the ends of each tube were taped with Tegaderm (3M, St Paul, MN, USA). ETTs were then soaked in a beaker containing $50 \mathrm{~mL}$ of lipase media maintained at $37^{\circ} \mathrm{C}$ and $200 \mathrm{rpm}$ for 24 hours. After 24 hours, the media in both the beaker and inside each of the tubes were replaced with fresh media. After each experiment, the tubes were washed with Milli-Q water, air-dried, and then sterilized using ethylene oxide exposure in a 16-hour sterilization 
cycle. Complete removal of the lipase solution was confirmed through sequential washings until the supernatant $\mathrm{pH}$ reached normal neural values. These surfaces were previously examined by scanning electron microscopy, showing random, nonhomogeneous nanoscale surface features. ${ }^{16}$

As stated by the vendor, the activity of the $R$. arrhisus lipase used to create the nanofeatures on the tubes was $10.5 \mathrm{U} / \mathrm{g}$, where one unit was defined as the amount of enzyme that catalyzed the release of $1 \mu \mathrm{mol}$ of oleic acid per minute at $\mathrm{pH} 7.4$ and $40^{\circ} \mathrm{C}$.

\section{Bacteria dynamic testing in a bench-top airway model}

Nanomodified ETTs were tested in an in vitro bench-top model of the pediatric airway adapted from the general design of the adult model in Hartmann et al. ${ }^{27}$ This custommade model can be seen in Figure 1. To avoid contamination, the system components were assembled using sterile techniques. At the beginning of each test, an ETT with $3.5 \mathrm{~mm}$ internal diameter was threaded through the oropharynxlarynx box into the trachea, and the cuff was carefully inflated. The oropharynx-larynx box and lung box were then filled with a total of $500 \mathrm{~mL}$ of sterile trypticase soy broth (TSB) medium. Lids were secured with tape of both the oropharynxlarynx box and the lung box to ensure sterility. A bacterial reservoir (Wheaton Cell Culture Spin Flask, Cole-Parmer, Vernon Hills, IL, USA) filled with $480 \mathrm{~mL}$ of sterile TSB was connected to the top lid of the oropharynx box, and a waste beaker was connected to the side of this box as well.

After the system was assembled, it was submerged in a water bath maintained at a constant temperature of $37^{\circ} \mathrm{C}$. The proximal end of the ETT was then connected to an Infant Star 950 ventilator (Puritan Bennett, Covidien, Mansfield, MA, USA). According to standard protocols, the positive end-expiratory pressure was set to $1 \mathrm{cmH}_{2} \mathrm{O}$ and the fraction of inspired oxygen $\left(\mathrm{FiO}_{2}\right)$ was set to 0.5 .
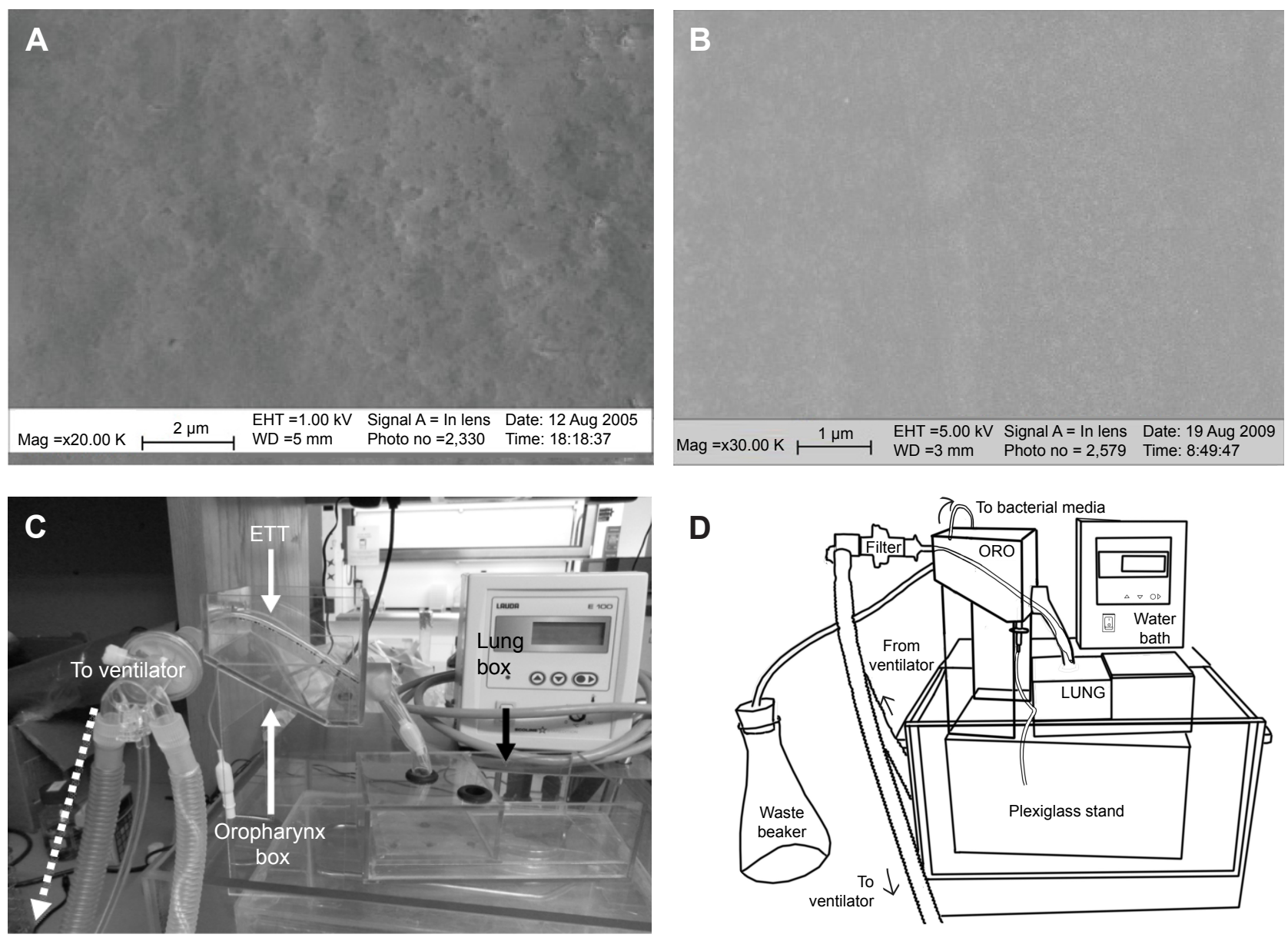

Figure I Experimental parameters of the dynamic lung box model.

Notes: SEM images of the surface roughness of $(\mathbf{A})$ nanomodified PVC ETT (Nano-R) and $(\mathbf{B})$ untreated PVC ETT placed in the lung box model. Nano-R: magnification $\times 30$ K. Untreated: magnification $\times 20 \mathrm{~K}$. Scale bars $=2 \mu \mathrm{m}$ and I $\mu \mathrm{m}$, respectively. Nano-R was modified with Rhizopus arrhisus. Schematics of lung box system showing (C) custommade pediatric airway model with ETT inserted and (D) key components of ventilated, continuously contaminated, bench-top model.

Abbreviations: SEM, scanning electron microscopy; PVC, polyvinyl chloride; ETT, endotracheal tube; Mag, magnification; EHT, extra high tension; WD, working distance; ORO, oropharynx-larynx box; LUNG, lung box. 
To begin the trial, the attached bacterial reservoir was inoculated with $10^{3}$ colony forming units (CFU)/mL of $P$. aeruginosa (ATCC 25668; American Type Culture Collection, Manassas, VA, USA). This bacterial medium was added to the oropharynx box using a peristaltic pump over the duration of the 24-hour test.

After each trial, the system was sterilized during a 16-hour cycle of ethylene oxide (Rhode Island Hospital, Providence, RI, USA). Additionally, sterile tests (where no bacterial medium was introduced to the system) were performed routinely to detect any cross contamination.

At the end of each trial, ETTs were removed from the system and cut into pieces using scissors measuring exactly $1.5 \mathrm{~cm}$, which did not result in any disruption of bacteria or the biofilm. To remove the biofilm from the surface of these pieces, a well-established vortex methodology ${ }^{28}$ was used. Briefly, sections of the ETT were added to $2 \mathrm{~mL}$ of TSB medium and vortexed for 1 minute at 3,000 rpm (Digital Vortex Mixer; Thermo Fisher Scientific, Waltham, MA, USA). Complete removal of bacteria was confirmed using scanning electron microscopy under standard conditions. The resulting supernatant was then serially diluted, plated on tryptic soy agar, and incubated overnight. Colony counts were performed to determine the number of CFUs on each segment of the tube. ${ }^{28}$

\section{Air flow analysis}

To fully understand the dynamic lung conditions within the in vitro model, a computational analysis of the fluid dynamics found within the ETT was conducted, as related in previous publications. ${ }^{16}$ Briefly, a finite element model of the exact orientation of the ETTs was constructed using COMSOL Multiphysics (v4.0a; COMSOL Group, Burlington, MA, USA). Air flow in the ETT was considered to be laminar, Newtonian, and incompressible. The boundary conditions used in this model were the following: 1) A no slip condition was applied at the wall of the ETT. 2) At the outlet, 1 atm was assumed, as this is a common assumption in clinical practice. 3) Finally, the inlet pressure (P) was prescribed using a square wave, as seen in the literature for a pressure-limited, constant-flow ventilator. ${ }^{29}$ The upper limit of the square wave was the positive inspiratory pressure minus the positive end expiratory pressure, while the lower limit was $1 \mathrm{~atm}$. Each peak of the square wave was exactly 0.416 seconds wide, which was the inspiratory time of the ventilator.

Initial conditions for the model were 1) an initial inlet velocity of $0 \mathrm{~m} / \mathrm{s}$ and 2) an initial inlet pressure of $1 \mathrm{~atm}$.

\section{Statistical analysis}

All experiments in the bench-top model were performed three times $(n=3)$, and the results are reported as mean \pm standard error of the mean. Either a paired $t$-test or two-way analysis of variance without replication was performed on all results.

\section{Results}

\section{Dynamic testing in a bench-top model}

For the current study, 24-hour testing performed in an in vitro model of the pediatric airway showed a marked variation in biofilm formation on consecutive segments along the length of the unmodified ETTs (Figures 2 and 3). Segments

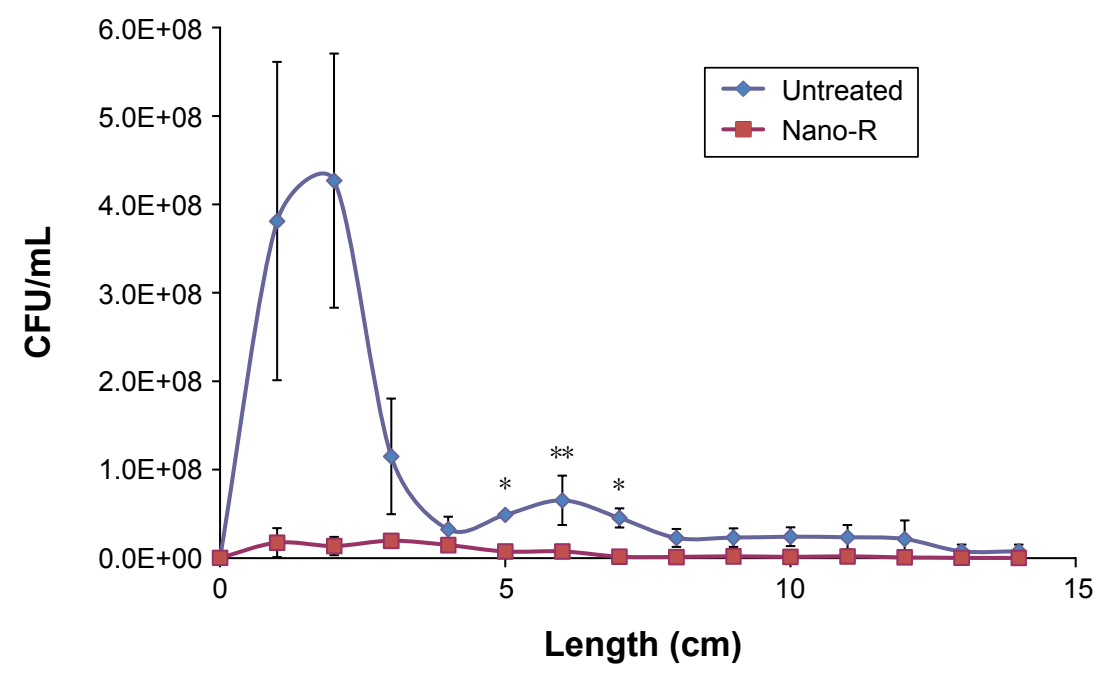

Figure 2 Dynamic lung system results for untreated versus nanomodified PVC ETTs.

Notes: Colony counts of $P$. aeruginos $a ; n=3$ ( $x$-axis length = longitudinal ETT length), error bars $\pm I S E, * P<0.05$ and $* * P<0.0 I$ compared to untreated ETTs at the same time points.

Abbreviations: PVC, polyvinyl chloride; ETT, endotracheal tube; SE, standard error; CFU, colony forming units. 


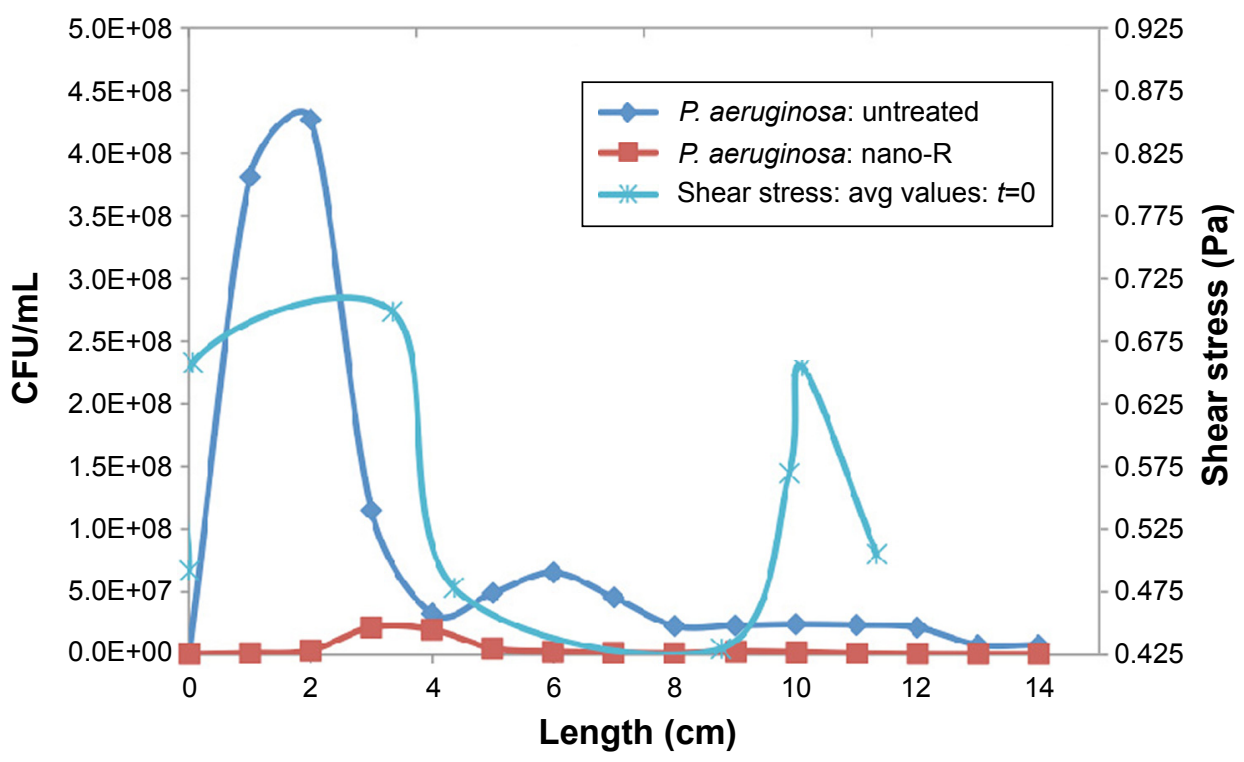

Figure 3 FEM model: average shear stress versus bacterial density $P$. aeruginosa.

Abbreviations: FEM, finite element model; $P$. aeruginosa, Pseudomonas aeruginosa; avg, average; CFU, colony forming units.

where the ETT curved, such as the segment at the entrance to the mouth and at the connection between the oropharynxlaynx box and the trachea, had larger amounts of biofilm formation. Most importantly, CFUs were significantly lower (up to a $1.5 \log$ reduction in $S$. aureus and up to a $2.7 \log$ reduction in $P$. aeruginosa) on the nanomodified ETTs than on control ETTs, all achieved, again, without the use of pharmaceutical drugs.

\section{Fluid analysis}

The average shear stress was calculated over each of the seven segments within the computational model and then was plotted along with bacterial distribution within the tube for $P$. aeruginosa (Figure 3).

Correlation coefficients between shear stress and bacterial density were found for both treated and untreated ETT. The correlation coefficient between shear stress and bacterial density for the nanomodified tubes with $P$. aeruginosa was determined to be $\sim 0.60$ while it was 0.55 for the untreated tubes. This suggests that influences besides shear stress (such as bacteria residence time, secondary velocity, and interactions with the wall) play a role in the determination of the bacterial distribution along the ETT.

Importantly, the velocity flow field and forces on the bacteria in the curved portions of the tube played a large role in determining bacterial distribution. It is, thus, these regions of the ETT in particular that deserve attention to decrease bacterial colonization, such as modifying ETT nanoscale roughness as was done here.

\section{Discussion}

Similar to those of previous static studies, ${ }^{16,28}$ results from this study showed significant reductions in the number of CFUs on the nanomodified ETT under a dynamic air flow environment (in fact, such reduction of bacteria was even more pronounced under flow). Specifically, log reductions of bacteria within the curved regions of the ETT were substantially increased during the dynamic studies for $P$. aeruginosa with a $2.7 \log$ reduction compared to a $S$. aureus's $1.2 \mathrm{log}$ reduction in previous studies. These dynamic results can be compared with only the percentage differences under static conditions. The pattern of bacterial distribution within the tube was also shifted, with $P$. aeruginosa forming closer to the proximal end of the ETT. This pattern was consistent for all tube materials, suggesting that hydrodynamic flow may modulate the attachment of the bacteria under flow and the subsequent colonization of the ETT. These results also suggest that different species of bacteria may either distribute on or colonize the surface of the ETT differently under dynamic conditions. Further testing needs to be conducted to determine whether this can be attributed to physical factors such as shear stress. Previous studies have shown that shear stress increases the duration of adhesion of both P. aeruginosa and Escherichia coli biofilms to coated surfaces. ${ }^{30,31}$

This reduction in the amount of bacteria seen on the ETTs in the in vitro model could be an effect of changes in the physical properties of the biofilm in reaction to shear stress. ${ }^{32}$ High shear forces have been shown in the literature to favor the creation of tight, rounded microcolonies of bacteria. ${ }^{33}$ The data 
from this experiment, coupled with the evidence of hydrodynamic effects on biofilm formation from the literature, suggests that a closer analysis of the effects of air flow and continuous contamination on biofilm formation in ETTs is needed.

The finite element model showed that regions of low wall shear $(0.20 \mathrm{~Pa})$ located along the lower wall of the ETT did correlate with experimental areas of higher bacterial density of $P$. aeruginosa. Values from the computational model were compared with those from the literature for shear stress in the healthy lung, which can vary widely based on the diameter and flow rate, but are between 0.0294 $\mathrm{Pa}$ and $0.1961 \mathrm{~Pa}$ in the trachea. ${ }^{34}$

Clearly, though, the most significant finding of this study is that modifying PVC ETTs with nanoscale surface features significantly decreased both gram-negative and gram-positive bacterial function without using antibiotics. Such results deserve further attention to elucidate a mechanism of action as well as translate such results to an in vivo model.

\section{Conclusion}

This study showed that etching with a fungal lipase can create nano-rough surface features on PVC ETTs to retard $P$. aeruginosa growth. Compared to previous static studies, ${ }^{16}$ the present dynamic study showed a greater decrease, a $2.7 \mathrm{log}$ reduction, in bacteria colonization on nanomodified ETTs compared to unmodified ETTs. The in vitro model also showed that dynamic flow conditions had an effect on the location of bacterial colonization on the ETT. A better understanding of the process of bacterial colonization and biofilm formation in the ETT could lead to better sampling in the clinical environment and eventually to improved diagnosis of VAP.

Testing of nanomodified ETT in an in vitro model under dynamic conditions provided key insights into their antimicrobial effectiveness. The differences in bacterial growth recorded along the length of the tube suggest that airflow and continuous contamination are significant influences on the initial sites of colonization in the ETT. Furthermore, the significant differences in growth between the nanomodified ETT and the untreated tubes provide further evidence that nanoroughness plays a key role in both bacterial colonization and biofilm formation. The larger decrease in bacterial growth found on the ETT surface in this dynamic study provides additional evidence that static testing of these materials may not reveal important interactions at the surface of these devices in vivo. Results of both static and dynamic experiments suggest that the nanomodified ETTs as created here could provide clinicians with a cost-effective tool to combat infections like VAP and should be studied further. Importantly, nanomodified ETTs were shown to decrease $S$. aureus and $P$. aeruginosa growth solely by changing the degree of nanofeatures on the tubes, and not by altering their surface chemistry or by the use of antibiotics.

\section{Acknowledgments}

The authors would like to thank the Hermann Foundation for funding. The authors would also like to thank Keiko Tarquinio and Daniel Cheng for both technical input to the paper and the SEM images.

\section{Disclosure}

The authors declare no conflicts of interest in this work.

\section{References}

1. Richards MJ, Edwards JR, Culver DH, Gaynes RP; National Nosocomial Infections Surveillance System. Nosocomial infections in pediatric intensive care units in the United States. Pediatrics. 1999;103(4):e39.

2. Elward AM, Warren DK, Fraser VJ. Ventilator-associated pneumonia in pediatric intensive care unit patients: risk factors and outcomes. Pediatrics. 2002;109(5):758-764.

3. Gaynes R, Edwards JR; National Nosocomial Infections Surveillance System. Overview of nosocomial infections caused by gram-negative bacilli. Clin Infect Dis. 2005;41(6):848-854.

4. Bigham MT, Amato R, Bondurrant P, et al. Ventilator-associated pneumonia in the pediatric intensive care unit: characterizing the problem and implementing a sustainable solution. J Pediatr. 2009;154(4): 582.e-587.e.

5. Srinivasan R, Asselin J, Gildengorin G, Wiener-Kronish J, Flori HR. A prospective study of ventilator-associated pneumonia in children. Pediatrics. 2009;123(4):1108-1115.

6. Raymond J, Aujard Y. Nosocomial infections in pediatric patients: a European, multicenter prospective study. Infect Control Hosp Epidemiol. 2000;21(04):260-263.

7. Brilli RJ, Sparling KW, Lake MR, et al. The business case for preventing ventilator-associated pneumonia in pediatric intensive care unit patients. Jt Comm J Qual Patient Saf. 2008;34(11):629-638.

8. Haley RW. Incidence and nature of endemic and epidemic nosocomial infections. In: Bennett JV, Brachman PS, Jarvis WR, editors. Bennett and Brachman's Hospital Infections. Boston: Lippincott Williams \& Wilkins; 2007:359-374.

9. Venkatachalam V, Hendley JO, Willson DF. The diagnostic dilemma of ventilator-associated pneumonia in critically ill children. Pediatr Crit Care Med. 2011;12(3):286-296.

10. Fischer JE, Ramser M, Fanconi S. Use of antibiotics in pediatric intensive care and potential savings. Intensive Care Med. 2000;26(7):959-966.

11. Foglia E, Meier MD, Elward A. Ventilator-associated pneumonia in neonatal and pediatric intensive care unit patients. Clin Microbiol Rev. 2007;20(3):409-425.

12. Olson ME, Harmon BG, Kollef MH. Silver-coated endotracheal tubes associated with reduced bacterial burden in the lungs of mechanically ventilated dogs. Chest. 2002;121(3):863-870.

13. Koerner RJ. Contribution of endotracheal tubes to the pathogenesis of ventilator-associated pneumonia. J Hosp Infect. 1997;35(2):83-89.

14. Mah TF, O'Toole GA. Mechanisms of biofilm resistance to antimicrobial agents. Trends Microbiol. 2001;9(1):34-39.

15. Cardinal P, Jessamine P, Carter-Snell C, Morrison S, Jones G. Contribution of water condensation in endotracheal tubes to contamination of the lungs. Chest. 1993;104(1):127-129. 
16. Machado MC, Cheng D, Tarquinio KM, Webster TJ. Nanotechnology: pediatric applications. Pediatr Res. 2010;67(5):500-504.

17. Sanvicens N, Marco MP. Multifunctional nanoparticleso properties and prospects for their use in human medicine. Trends Biotechnol. 2008;26(8):425-433.

18. Klein J. Probing the interactions of proteins and nanoparticles. Proc Natl Acad Sci U S A. 2007;104(7):2029-2030.

19. Liu H, Webster TJ. Nanomedicine for implants: a review of studies and necessary experimental tools. Biomaterials. 2007;28(2):354-369.

20. Lichter JA, Thompson MT, Delgadillo M, Nishikawa T, Rubner MF, Van Vliet KJ. Substrata mechanical stiffness can regulate adhesion of viable bacteria. Biomacromolecules. 2008;9(6):1571-1578.

21. Diaz C, Cortizo MC, Schilardi PL, Saravia SGG, Mele MAFL. Influence of the nano-micro structure of the surface on bacterial adhesion. Mat Res. 2007;10(1):11-14.

22. Berger SA, Talbot L. Flow in curved pipes. Annu Rev Fluid Mech. 1983;15:461-512.

23. Rusconi R, Lecuyer S, Guglielmini L, Stone HA. Laminar flow around corners triggers the formation of biofilm streamers. $J R$ Soc Interface. 2010;7(50):1293-1299.

24. Rupp CJ, Fux CA, Stoodley P. Viscoelasticity of Staphylococcus aureus biofilms in response to fluid shear allows resistance to detachment and facilitates rolling migration. Appl Environ Microbiol. 2005; 71(4):2175-2178.

25. Donlan RM. Biofilms: microbial life on surfaces. Emerg Infect Dis. 2002; 8(9):881-890.

26. Machado M, Tarquinio K, Webster TJ. Decreased Staphylococcus aureus biofilm formation on nanomodified endotracheal tubes: a dynamic airway model. Int J Nanomedicine. 2012;7:3741-3750.
27. Hartmann M, Guttmann J, Müller B, Hallmann T, Geiger K. Reduction of the bacterial load by the silver-coated endotracheal tube (SCET), a laboratory investigation. Technol Health Care. 1999;7(5):359-370.

28. Seil JT, Rubien NM, Webster TJ, Tarquinio KM. Comparison of quantification methods illustrates reduced Pseudomonas aeruginosa activity on nanorough polyvinyl chloride. J Biomed Mater Res B Appl Biomater. 2011;9B(1):1-7.

29. Dellinger RP, Jean S, Cinel I, et al. Regional distribution of acoustic-based lung vibration as a function of mechanical ventilation mode. Crit Care. 2007;11(1):R26.

30. Meinders JM, van der Mei HC, Busscher HJ. Physicochemical aspects of deposition of Streptococcus thermophilus-b to hydrophobic and hydrophilic substrata in a parallel-plate flow chamber. J Colloid Interface Sci. 1994;164:355-363.

31. Lecuyer S, Rusconi R, Shen Y, et al. Shear stress increases the residence time of adhesion of Pseudomonas aeruginosa. Biophys J. 2011;100(2): $341-350$.

32. Katsikogianni M, Missirlis YF. Concise review of mechanisms of bacterial adhesion to biomaterials and of techniques used in estimating bacteria-material interactions. Eur Cell Mater. 2004;8:37-57.

33. Perkins J, Mouzakes J, Pereira R, Mannings S. Bacterial biofilm presence in pediatric tracheotomy tubes. Arch Otolaryngol Head Neck Surg. 2004;130(3):339-343.

34. Nucci G, Suki B, Lutchen K. Modeling airflow-related shear stress during heterogeneous constriction and mechanical ventilation. $J \mathrm{Appl}$ Physiol. 2003;95(1):348-356.
International Journal of Nanomedicine

\section{Publish your work in this journal}

The International Journal of Nanomedicine is an international, peerreviewed journal focusing on the application of nanotechnology in diagnostics, therapeutics, and drug delivery systems throughout the biomedical field. This journal is indexed on PubMed Central, MedLine, CAS, SciSearch $\AA$, Current Contents ${ }^{\circledR} /$ Clinical Medicine,

\section{Dovepress}

Journal Citation Reports/Science Edition, EMBase, Scopus and the Elsevier Bibliographic databases. The manuscript management system is completely online and includes a very quick and fair peer-review system, which is all easy to use. Visit http://www.dovepress.com/ testimonials.php to read real quotes from published authors. 